\title{
Particulate Air Pollutants and Respiratory Diseases
}

\author{
An-Soo Jang
}

Additional information is available at the end of the chapter

http://dx.doi.org/10.5772/51363

\section{Introduction}

Air pollution is composed of a mixture of toxins, consisting of particles and gases emitted in large quantities from many different combustion sources, including cars and industries. A variety of anthropogenic and natural particle sources are present in ambient air. Throughout the past decade, the composition of air pollution has changed in developed countries from classical type 1 pollution, consisting of sulfur dioxide and large dust particles, to modern type II pollution, characterized by nitrogen oxides, organic compounds, ozone, and ultrafine particles (Schäfer \& Ring, 1997).

Particulate matter (PM) is the principal component of indoor and outdoor air pollution. PM is a complex, multi-pollutant mixture of solid and liquid particles suspended in gas (Ristovski et al., 2011). PM originates from a variety of manmade and natural sources. Natural sources include pollen, spores, bacteria, plant and animal debris, and suspended materials. Human-made sources include industrial emissions and combustion byproducts from incinerators, motor vehicles, and power plants. Indoor sources include cigarette smoking, cooking, wood and other materials burned in stoves and fireplaces, cleaning activities that resuspend dust particles, and the infiltration of outdoor particles into the indoor environment (2003, McCormack et al., 2008).

Vehicle emissions are the predominant source of fine PM $(2.5 \mu$ PM with an aerodynamic diameter $<2.5 \mu \mathrm{m}$ ) in urban areas, where most people live globally (Ristovski et al., 2011). Airborne PM less than $10 \mu \mathrm{m}$ in aerodynamic diameter (PM 10) is a complex mixture of materials with a carbonaceous core and associated materials such as organic compounds, acids, and fine metal particles (Pagan et al., 2003).

The physical properties of PM including the mass, surface area, and number/size/ distribution of particles, as well as their physical state, influence respiratory health in 
different ways (Ristovski et al., 2011). The primary exposure mechanism to PM and other particle sources is by inhalation (Ristovski et al., 2011).

Growing epidemiologic evidence indicates that inhalation of airborne PM increases respiratory and cardiac mortality and morbidity, and produces a range of adverse respiratory health outcomes such as asthma, lung function decline, lung cancer, and chronic obstructive pulmonary disease (COPD) (Ayres et al., 2008, Ristovski et al., 2011). Epidemiologic data indicate that air pollution also aggravates asthma, with the exacerbation correlating with levels of environmental particles (Schwartz et al. 1993). Likewise, the rate of decline seen in COPD patients correlates with the level of air pollution where the patients live (Pope \& Kanner, 1993).

PM induces inflammation, innate and acquired immunity, and oxidative stress. It also increases innate and adaptive immune responses in both animals and humans. That derived from traffic and various industries is associated with allergic airway disorders, including asthma. Understanding the mechanisms of lung injury from PM will enhance efforts to protect at-risk individuals from the harmful respiratory effects of air pollutants. PM functions as an adjuvant inducing lung inflammation to allergens or respiratory viruses. Inhalation of PM aggravates respiratory symptoms in patients with chronic airway diseases, but the mechanisms underlying this response remain poorly understood. This review focuses on the adverse effects of exposure to ambient PM air pollution on the exacerbation, progression, and development of asthma, COPD, and respiratory diseases. It also attempts to offer insights into the mechanisms by which particles may influence airway inflammation, and several mechanisms that may explain the relationship between particulate air pollutants and respiratory diseases are discussed.

\section{Adverse effects of PM on respiratory diseases identified in epidemiologic studies (Figure 1)}

PM is a mixture of organic and inorganic solid and liquid particles of different origins, size, and composition. It is a major component of urban air pollution and greatly effects health. Penetration of the tracheobronchial tract is related to particle size and the efficiency of airway defense mechanisms (D'Amato et al., 2010). Particles smaller than $10 \mu \mathrm{m}$ can get into the large upper branches, just below the throat, where they are caught and removed (by coughing and spitting or swallowing). Particles smaller than $5 \mu \mathrm{m}$ can get into the bronchial tubes at the top of the lungs, while particles smaller than $2.5 \mu \mathrm{m}$ in diameter can penetrate the deepest (alveolar) portions of the lung. If these particles are soluble in water, they pass directly into the blood in the alveolar capillaries. If they are insoluble in water, they are retained deep within the lungs for extensive periods of time. About $60 \%$ of PM10 particles (by weight) have a diameter of $2.5 \mu \mathrm{m}$ or less.

According to the World Health Organization, 24\% of the global disease burden and 23\% of all deaths are attributable to environmental factors (Pruss-Ustun \& Corvalan, 2006). The cause of, and route of exposure that lead to, disease and death is often complex and poorly 


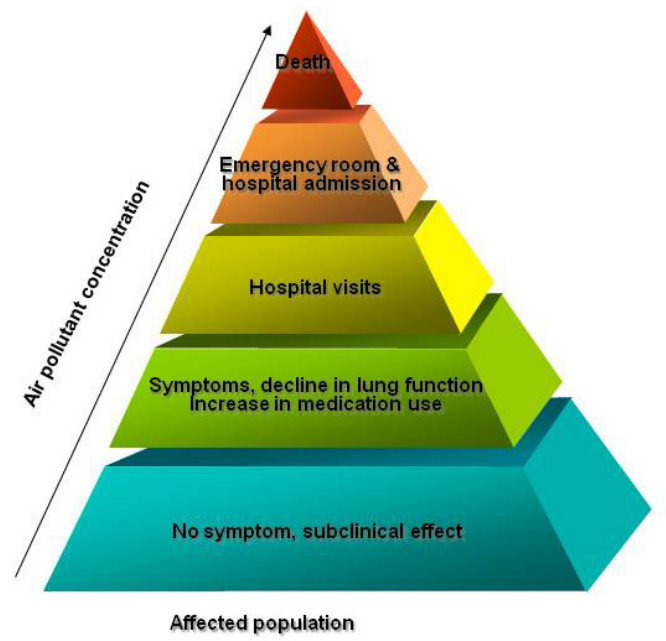

Figure 1. Particulate matter effect on respiratory diseases.

understood. The increased air pollution emanating from traffic and various industries has caused an increase in the incidence of allergic diseases. In children, acute exposure to air pollution is associated with increased respiratory symptoms and decreased lung function. Chronic exposure to increased levels of inhalable particles is associated with up to a threefold increase in non-specific respiratory symptoms, such as chronic cough, asthma, and chronic airway diseases (Nicolai, 1989). Exposure to heavy traffic leads to significant increases in respiratory symptoms, while a direct effect of traffic on asthma initiation has been documented (Nicolai, 1989). Indeed, outdoor air pollution levels have been associated with adverse health in asthma subjects (Nicolai, 1989). Exposure to traffic-related air pollution, in particular diesel exhaust particles (DEP), may lead to reduced lung function in children living near major motorways (Brunekreef et al., 1997). The prevalence of airway hyper-responsiveness (AHR) has increased over the last few decades, potentially because of environmental factors. Air pollution is convincingly associated with many signs of asthma aggravation, including pulmonary function decrease, increased AHR, additional visits to emergency departments, increased hospital admissions, increased medication use, and more reported symptoms. It is also associated with inflammatory changes, interactions between air pollution and allergen challenges, and changes in immune response (Koenig, 1999). There is a significant association between traffic-related air pollution and wheezing in children (Hisch et al., 1999), and exposure to DEPs may reduce lung function in children living near motorways. DEPs account for most airborne PM in the world's largest cities (Rield \& Diaz-Sanchez, 2005), and are composed of fine $(2.5-0.1 \mu \mathrm{m})$ and ultra-fine $(<0.1 \mu \mathrm{m})$ particles, although primary DEPs can coalesce to form aggregates of varying sizes. Acute exposure to DEPs causes irritation of the nose and eyes, headache, lung function abnormalities, fatigue, and nausea, while chronic exposure is associated with cough, sputum production, and diminished lung function (McCreanor et al., 2007). 
There is strong evidence that episodes of air pollution aggravate respiratory disease, especially asthma. A study of the relationship between fine PM and emergency room visits for asthma in the metropolitan Seattle area was designed to substantiate that air pollution was a risk factor for asthma (Mortimer et al., 2002). Using Poisson regression analyses that controlled for weather, season, time trends, age, hospital, and day of the week, a significant association was found between fine particles measured at the monitoring station and visits to emergency departments in eight nearby participating hospitals (Mortimer et al., 2002).

There are relatively few studies on the correlation between indoor PM and asthma. A subgroup of 10 children not using inhaled corticosteroids in Seattle were found to have decreased pulmonary function associated with indoor PM2.5 exposure (Koenig et al., 2005). Moreover, PM2.5 originating from indoor sources was more potent in decreasing lung function than was PM exposure outdoors (Koenig et al., 2005). A California study of 19 predominantly white children found significant decreases in lung function (FEV1) associated with indoor PM. While this study found associations between ambient PM and lung function, a stronger association was found with indoor central site PM concentrations than outdoor PM (McConnellet et al., 2003). Significant determinants of indoor PM concentrations include smoking, sweeping, and stove use (McCormack et al., 2008), activities that are modifiable and provide opportunities for exposure reduction. Smoking has been a major source of indoor particulates over the last several decades, with more than $30 \%$ of all U.S. children exposed to secondhand smoke (Winickoff et al., 2005).

Asthma symptoms are associated with indoor coarse PM. For example, in a previous study, every $10 \mathrm{mg} / \mathrm{m}^{3}$ increase in indoor PM 2.5-10 concentration led to a 6\% increase in the number of days of coughing, wheezing, or chest tightness, after adjusting for age, race, sex, socioeconomic status, season, indoor fine PM, and ambient fine and coarse PM concentrations (Breysse et al., 2010). This study also found that higher indoor coarse PM concentrations were also associated with increased incidences of symptoms severe enough to slow a child's activity, cause wheezing that limited speaking ability, nocturnal symptoms, and rescue medication use; and although outdoor coarse PM was not associated with increased asthma symptoms or rescue medication use, fine PM was positively associated with respiratory symptoms and rescue medication use (Breysse et al., 2010). These findings demonstrate that both indoor coarse and fine PM distinctly affect respiratory health in children with asthma.

Although fine PM may be capable of reaching the alveoli, the regions responsible for gas exchange, the deposition of coarse PM in upper airways and subsequent bronchial hyperreactivity may be responsible for the symptomatic response measured in preschool children (Breysse et al., 2010).

In asthmatic children attending school in urban Amsterdam, black smoke was the most important air pollution indicator associated with acute changes in lung function, respiratory symptoms, and medication use (Gielen et al., 1997). In one polluted area (Jang et al., 2003), 670 schoolchildren (100\%) had normal pulmonary function, while 257 (38.3\%) had AHR. A significantly greater proportion of children had AHR in the polluted area $(45.0 \%[138 / 306]$, $6.50 \pm 0.48)$ than in rural $(31.9 \%$ [52/163], $9.84 \pm 0.83)$ or coastal $(33.3 \%$ [67/201], $7.17 \pm 0.68)$ areas. 
Schoolchildren with atopy had lower PC20 levels than those without (5.98 \pm 0.60 vs. $8.15 \pm 0.45, \mathrm{p}<0.001)$. In a multiple logistic regression model, a positive allergy skin test and living in the polluted area near a chemical factory were independently associated with AHR (odds ratio for location=2.4875, CI 1.6542-3.7406, $\mathrm{P}<0.01$; odds ratio for allergy skin test $=1.5782$, CI 1.1130 - 2.2379, $\mathrm{p}<0.05$ ), when adjusted for sex, parents' smoking habits, age, body mass index, nose symptoms, and lung symptoms. This suggests that air quality near the polluted area contributes to the development of AHR, and that controlling air pollution is important for preventing the development of asthma. Asthma, a complex disease influenced by both environmental and genetic factors, is common and the prevalence is increasing worldwide (Holgate, 1999). Indoor environmental factors thought to modify asthma severity include pollutants such as PM, nitrogen oxides, secondhand smoke, and allergens from pests, pets, and molds (Diette, 2008). In contrast to the outdoors, individuals have a greater ability to modify indoor environmental exposure risks, making indoor air pollution an attractive target for disease prevention (Breysse et al., 2010).

DEP plays a role in increasing asthma prevalence, although a causal relationship has yet to be established. In a modification of the classical ovalbumin sensitization and challenge model, mice were exposed to intranasal DEP and challenged with aerosolized DEP on days 6-8 (Song et al., 2008). Delivery of aerosolized DEP, following exposure with intranasal DEP, induced a significant increase in methacholine-induced airway hyper-responsiveness. Pope and Dockery (Pope \& Dockery, 2006) suggested that there is a $0.6-2.2 \%$ increase in respiratory mortality risk for a $10 \mu \mathrm{g} / \mathrm{m}^{3}$ increase in ambient PM. Indeed, many cohort studies have demonstrated that airborne PM, of which PM is a major contributor (Robinson et al., 2010), causes respiratory mortality and morbidity (Pope \& Dockery, 2006).

A cross-sectional study of 20,000 children between 6 and 12 years old found a weak association between decreased pediatric lung function and secondhand smoking (Moshammer et al., 2006). Also, children living in homes that use organic fuels for cooking, heating, and lighting are exposed to much higher levels of PM than children living in homes where parents smoke and use clean fuels (e.g., a mean indoor level of $200 \mathrm{mg} / \mathrm{m}^{3}$ PM per 24 h; Jiang \& Bell, 2008).

There are many sources of air pollution in the home environment. Air pollution inside homes consists of a complex mixture of agents penetrating from ambient outdoor air, and agents generated by indoor sources. Indoor pollutants can vary in their potential health hazard and intensity, as well as in their distribution across geographic areas, cultural backgrounds, and socioeconomic status (Breysse et al., 2010).

In a British cohort of 4,400 preschool children, a significant association was found between exposure to primary PM10 at the home address and prevalence of coughing without a cold (Pierse et al, 2006). Data from the Third U.S. National Health and Nutrition Examination Survey (1988-1994) found that exposure to environmental tobacco smoke is associated with increased prevalence of pediatric asthma, wheezing, and chronic bronchitis (Gergen et al., 1998).

Entering adulthood with impaired lung function is a non-specific risk factor for respiratory disease in adulthood. Lower lung function predisposes children to further structural 
damage to the developing lung (Grigg, 2009). COPD is the non-specific terminology commonly used to describe the spectrum of diseases limiting respiratory airflow, e.g., asthma, chronic bronchitis, and emphysema (Matthay, 1992). There are several reasons why environmental exposures in childhood are relevant to the pathogenesis of COPD (Grigg, 2009). First, attenuation of lung growth due to air pollution in childhood is a risk factor for adult-onset respiratory disease. Second, there may be common cellular and molecular mechanisms underlying impaired pulmonary innate host defenses in children exposed to air pollution, and susceptibility to infection in COPD. Third, lung damage initiated in childhood may contribute to an emerging global health issue, namely, COPD due to smoke exposure.

Studies showing an association between lifelong organic smoke and the development of COPD in nonsmoking women provides a direct link between exposure of children to PM and increased vulnerability to respiratory disease in adulthood (Grigg, 2009). Chronic exposure to PM (Grigg, 2009) likely interferes with maximal lung function attainment in childhood, accelerates lung function decline in adulthood, stimulates airway mucus production, and impairs pulmonary innate immunity. Similar associations between air particulate pollution (PM10 or PM2.5) and hospital admissions for COPD have been reported for a variety of urban areas (Yang et al., 2005). The strong association between respiratory hospital admissions and PM10 pollution (Pope, 1991) supports the role of PM10 in the incidence and severity of respiratory disease.

Long-term studies usually use a cohort design when comparing mortality across populations, and vary in their long-term exposure to air pollution. An overall reduction in PM 2.5 levels over time results in reduced long-term risk of death due to cardiovascular and/or respiratory disease (Laden et al., 2006). A large European cohort study of mortality and air pollution showed smaller effective estimates, which were significant only for allcause and respiratory mortality (Beelen et al., 2008). Epidemiological studies from controlled human exposure to toxins have identified characteristics of populations that may be more susceptible to PM-related health issues (Sacks et al., 2011): children and older adults with preexisting cardiovascular and respiratory diseases, populations with lower income and less education, and the presence of genetic polymorphisms. In addition, PM-related health effects are sometimes observed in individuals with diabetes, COPD, and increased body mass index. A cohort study of Swiss adults demonstrated that a decrease in ambient PM10 was associated with reduced respiratory symptoms (Schindler et al., 2009).

Given the increasing evidence that air pollution has both short- and long-term effects on health, the public health impact of reducing pollutant levels has gained attention. A large study across 211 U.S. counties demonstrated significant improvements in life expectancy related to reductions in PM2.5 concentrations (Pope et al., 2009).

\section{Molecular mechanisms in in vitro and in vivo studies (Figure 2)}

Because the lung interfaces with the external environment and is frequently exposed to air pollutants, such as PM, it is prone to oxidant-mediated cellular damage ( $\mathrm{Nel}$ et al., 2006). 
The adverse health effects of particulate pollutants may be explained by several mechanisms, including innate immunity, adaptive immunity, and the production of reactive oxygen species (Nel et al., 2006).

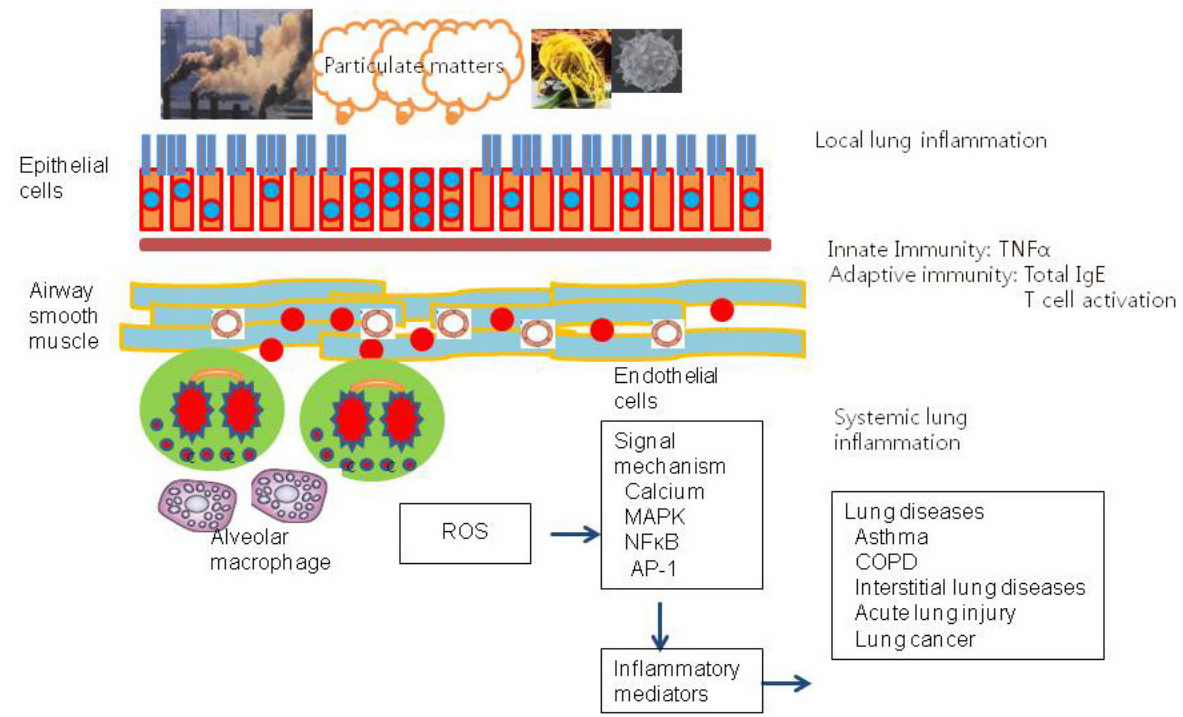

Figure 2. Proposed mechanism of lung diseases by PM.

\section{Innate immunity}

The pathways associated with acute inflammation in response to particle exposure involve an orchestrated sequence of events, mediated in part by chemokines and cytokines (Seagrave, 2008). Particles larger than $10 \mu \mathrm{m}$ generally get caught in the nose and throat, and never enter the lungs (Yang \& Omaye, 2009). After inhalation of PM, phagocytic cells including neutrophils and macrophages are recruited to the foreign particle by cytokines and chemokines, and transported by the mucociliary escalator for removal (Donaldson and Tran, 2002). PM induces the release of inflammatory cytokines, such as IL-6, IL-8, GM-CSF, and TNF- $\alpha$ (Stone et al., 2007) from immune cells (e.g., macrophages) as well as structural airway cells (Totlandsdal et al., 2010).

DEPs exert their effect through agents such as polyaromatic hydrocarbons (PAHs). The particles are deposited on the airway mucosa; their hydrophobic nature allows them to diffuse easily through cell membranes and to bind to cytosolic receptor complexes. Through subsequent nuclear activity, PAHs can modify both cell growth and cell differentiation programs.

Experimental studies have shown that DEP-PAHs can modify the immune response in animals and humans and modulate airway inflammatory processes. In other words, DEPs exert an adjuvant immunological effect on IgE synthesis in atopic subjects, thereby causing 
sensitization to airborne allergens (Diaz Sanchez et al., 1997). They also cause respiratory symptoms and modify the immune response in atopic subjects (Rield \& Diaz-Sanchez, 2005, Diaz Sanchez et al., 1997), and can interact with aeroallergens to enhance antigen-induced responses, with the result that allergen-specific IgE levels are up to 50-fold greater in allergic patients stimulated with DEPs and allergens than in patients treated with allergen alone (Diaz Sanchez et al., 1997). A combined challenge of DEPs and ragweed allergen markedly increases the expression of human nasal ragweed-specific IgE in vivo and skews cytokine production to a type 2 helper T-cell pattern (Diaz Sanchez et al., 1997).

Chitin is commonly found in organisms including parasites, fungi, and bacteria, but does not occur in mammalian tissues (Guo et al., 2000), allowing for selective antimicrobial activity of chitinase. Macrophage-synthesized $\mathrm{Ym} 1$ and $\mathrm{Ym} 2$ are homologous to chitinase, and have chitinase activity (Sun et al., 2001, Jin et al., 1998). Through the IL-4/STAT 6 signal transduction pathway, Ym1 was implicated in allergic peritonitis (Welch et al., 2002). Acid mammalian chitinase may also be an important mediator of IL13-induced responses in Th2 disorders, such as asthma (Zhu et al., 2004). Indeed, polymorphisms in acid mammalian chitinase are associated with asthma, further supporting the involvement of acid mammalian chitinase in asthma development (Bierbaum et al., 2005). DEP induces airway hyper-responsiveness as well as Ym mRNA expression, a Th2 cell-biased response by activated macrophages. The chitinase $\mathrm{Ym} 1$ is expressed in the spleen and lungs, with lower expression in the thymus, intestine, and kidney, whereas $\mathrm{Ym} 2$ is expressed at high levels in the stomach, with lower levels in the thymus and kidney (Ward et al., 2001). Conserved STAT6 sites probably account for the similar, striking induction of $\mathrm{Ym} 1$ and $\mathrm{Ym} 2$ expression in Th2-type environments. In a murine model of DEP exposure, with BALB/c mice exposed intranasally to DEP followed by a DEP challenge, upregulation of lung-specific expression of $\mathrm{Ym} 1$ and $\mathrm{Ym} 2$ transcripts was seen relative to mice that were not exposed nor similarly challenged (Song et al., 2008). Alveolar macrophages play an important role in particleinduced airway and lung inflammation via direct production of IL-13. Treatment of epithelial cells with bovine serum albumin-coated titanium dioxide particles led to 20 altered proteins on two-dimensional gels, which were further analyzed by nano-LC-MS/MS. These proteins included defense-related, cell-activating, and cytoskeletal proteins implicated in responses to oxidative stress (Kang et al., 2005). Titanum dioxide (TiO2) treatment increased macrophage migration-inhibitory factor (MIF) mRNA levels. MIF was expressed primarily in the epithelium and was elevated in lung tissues and bronchoalveolar lavage (BAL) fluids of TiO2-treated rats, compared to sham-treated rats. Carbon and DEPs also induce the expression of MIF protein in epithelial cells. The regulation and function of chitinase has not been well explored in air pollution asthma models. However, in one study, Ym1 was one of the most highly induced IL-4 target genes, exhibiting at least a 70-fold increase in macrophage populations (Kang et al., 2005). Nitric oxide (NO) was shown to be a short-lived molecule that causes vasodilation and bronchodilation (Moncada et al., 1991). In that study, the nitrite concentration in BAL fluids, indicative of the in vivo generation of NO in the airways, was significantly greater in DEP-exposed animals than in the control group. In another study, alveolar macrophages produced nitrite during in vitro exposure to DEP 
particles $(50 \mu \mathrm{g} / \mathrm{ml})$, with maximal induction $4 \mathrm{~h}$ after exposure (Song et al., 2008). The inflammatory effects of PM 10 were demonstrated in experimental animal studies following direct instillation into the lung, prior to human studies that showed the pulmonary effects after experimental exposure to PM (Ghio \& Devlin, 2001). Clinically, PM 10 particles likely provoke airway inflammation via the release of mediators that exacerbate lung disease in susceptible individuals (Seaton et al., 1995); even a single exposure compromises a host's ability to handle ongoing pulmonary infections (Zelikoff et al., 2003). Fine and ultra-fine particles directly stimulate macrophages and epithelial cells to produce inflammatory cytokines such as TNF- $\alpha$, TGF- $\beta 1$, GM-CSF, PDGF, IL-6, and IL-8 (Fugii et al., 2001), and reactive oxygen species are responsible for acute and chronic lung inflammation ( $\mathrm{Li}$ et al., 2003).

\section{Adaptive immunity}

PM induces a Th2-like environment, with the overproduction of IL-4 and IL-13 (Kang et al., 2005). We found that IL-13 mRNA levels in lung tissue extracts were significantly increased $24 \mathrm{~h}$ after treatment with $\mathrm{TiO} 2$ particles, compared to sham-treated rats (Kang et al., 2005). IL-13 levels were also significantly increased in the BAL fluids of TiO2-treated rats $72 \mathrm{~h}$ after treatment $(n=8)$, relative to sham-treated rats $(n=8)$. To investigate the time- and dosedependency of macrophage IL-13 production, purified alveolar macrophages were stimulated with 1,10 , and $40 \mu \mathrm{g} / \mathrm{ml} \mathrm{TiO} 2$ for 24,48 , and $72 \mathrm{~h}$ ( $\mathrm{n}=6$ in each experiment). The control group $(n=6)$ consisted of untreated alveolar macrophages. IL-13 levels in the supernatants of the macrophage cultures were measured by ELISA. Macrophages that were cultured for $48 \mathrm{~h}$ with TiO2 produced IL-13 in a dose-dependent manner. In addition, 10 $\mu \mathrm{g} / \mathrm{ml} \mathrm{TiO} 2$ significantly enhanced IL-13 production relative to controls. IL-13 protein production increased in a time-dependent manner, and peaked $48 \mathrm{~h}$ after $\mathrm{TiO} 2$ exposure. Using immunohistochemical staining, we also found that $\mathrm{TiO} 2$-engulfing macrophages were the main source of IL-13 in TiO2-particle-induced lung inflammation. Taken together, our results suggest that alveolar macrophages may be major effectors of innate immunity by modulating inflammatory responses towards a Th2-phenotype by producing IL-13, as seen in the adaptive immune response (Figure 3). Proteomics offers a unique means of analyzing expressed proteins, and was successfully used to examine the effects of oxidative stress at the cellular level. In addition to revealing protein modifications, this approach can also be used to look at changes in protein expression levels (Blackford et al., 1997). In a previous study, 20 proteins were identified (Table 1) whose expression levels in the human bronchial epithelial cell line BEAS-2B changed in response to $\mathrm{TiO} 2$ particle exposure (Cha et al., 2007). These proteins included defense-related, cell-activating, and cytoskeletal proteins implicated in the response to oxidative stress, and can be classified into four groups according to the pattern of their TiO2-induced change in expression over time (Figure 4). One protein, MIF, was induced at the transcriptional level by stimulation of cells with any of three different particulate molecules; expression of MIF increased in lungs of TiO2-instilled rats. These results indicate that some of these proteins may serve as mediators of, or markers for, airway disease caused by exposure to PM. 
A

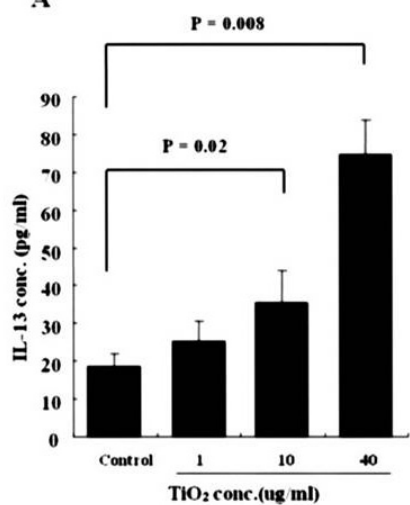

B

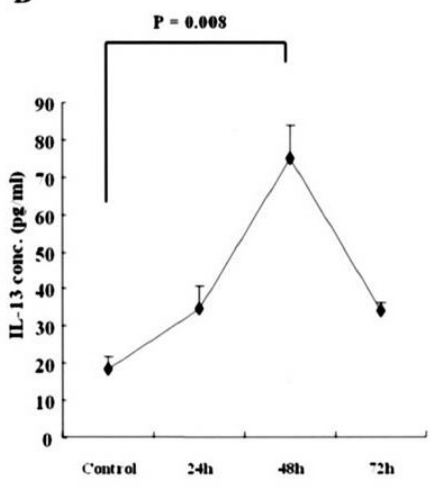

Figure 3. Time and dose responses of IL-13 production by macrophages exposed to $\mathrm{TiO} 2$ particles. Purified alveolar macrophages stimulated with 1, 10, and $40 \mathrm{~g} / \mathrm{ml} \mathrm{TiO} 2$ for 24,48 , and $72 \mathrm{~h}$ ( $\mathrm{n}=6$ in each experiment). The control group $(\mathrm{n}=6)$ consisted of unstimulated alveolar macrophages. The IL-13 in the 48-h culture supernatants is produced in a dosedependent manner after $\mathrm{TiO} 2$ treatment (A). $\mathrm{TiO} 2$ concentrations $10 \mathrm{~g} / \mathrm{ml}$ significantly enhance IL-13 production when compared with the control group. The production of IL-13 protein is increased in a time-dependent manner and peaks $48 \mathrm{~h}$ after TiO2 stimulation $(\mathrm{B})$. The results are expressed as means \pm SEM. ${ }^{*}$ Significant difference $(\mathrm{P}<0.05)$ when compared with the control group.

\begin{tabular}{|c|c|c|c|c|c|}
\hline No. & Protein name & Abbreviation & Accession no. & Amino acid sequence & $\begin{array}{l}\mathrm{pl} / \text { molecular } \\
\text { mass }(\mathrm{Da})\end{array}$ \\
\hline \multicolumn{6}{|c|}{ Group 1} \\
\hline 1 & ATPase, $\mathrm{H}^{+}$-transporting & ATP6V1B2 & 19913428 & (K)AWQVFEGTSGIDAK(K) & $5.4 / 55,401.6$ \\
\hline 2 & Keratin $6 \mathrm{~A}$ & K6A & 15559584 & (K)ADTLTDEINFLR(A) & $8.09 / 60,018.2$ \\
\hline 3 & Macrophage migration-inhibitory factor & MIF & 30583135 & (K)LLCGLLAER(L) & $7.73 / 12,476.4$ \\
\hline \multicolumn{6}{|c|}{ Group 2} \\
\hline 4 & Heat-shock 60-kDa protein 1 & HSPD1 & 31542947 & (K)VGEVIVTKDDAmLLK(G) & $5.7 / 61,055.0$ \\
\hline 5 & RuvB-like 2 & RUVBL2 & 5730023 & (R)ALESDMAPVLIMATNR(G) & $5.49 / 51,156.8$ \\
\hline 6 & Proliferating cell nuclear antigen & PCNA & 33239451 & (R)DLSHIGDAVISCAK(D) & $4.57 / 28,769.0$ \\
\hline 7 & Transaldolase 1 & TALDO1 & 16307182 & (K)ALAGCDFLTISPK(L) & $9.07 / 35,329.0$ \\
\hline 8 & Chloride intracellular channel 1 & CLIC1 & 14251209 & (K)LAALNPESNTAGLDIFAK(F) & $5.09 / 259,229$ \\
\hline \multicolumn{6}{|c|}{ Group 3} \\
\hline 9 & Replication licensing factor MCM7 & MCM7 & 20981696 & (R)TQRPADVIFATVR(E) & $6.08 / 81,281.4$ \\
\hline 10 & Calpain 1 & CAPN1 & 12408656 & (R)DMETIGFAVYEVPPELVGQPAVHLKR(D) & $5.49 / 81,890.5$ \\
\hline 11 & Ribonuclease/angiogenin inhibitor & RNH1 & 15029922 & (K)ELSLAGNELGDEGAR(L) & $4.83 / 48,368.0$ \\
\hline 12 & Vimentin & VIM & 62414289 & (K)FADLSEAANR(N) & $5.00 / 52,438.6$ \\
\hline 13 & $26 \mathrm{~S}$ proteasome subunit 9 & PSMD9 & 2150046 & (R)DIQENDEEAVQVK(E) & $6.08 / 47,448.0$ \\
\hline 14 & Actin-related protein 2 & ACTR2 & 15778930 & (K)HIVLSGGSTMYPGLPSR(L) & $6.29 / 44,761.0$ \\
\hline 15 & $\begin{array}{l}26 \mathrm{~S} \text { proteasome-associated pad1 } \\
\text { homologue }\end{array}$ & PSMD14 & 5031981 & (R)AVAVVVDPIQSVK(G) & $6.06 / 34,577.3$ \\
\hline \multicolumn{6}{|c|}{ Group 4} \\
\hline 16 & $\begin{array}{l}\text { PRP19/PSO4 pre-mRNA processing } \\
\text { factor } 19 \text { homologue }\end{array}$ & PRP19 & 7657381 & (R)QELSHALYQHDAACR(V) & $6.14 / 55,181.1$ \\
\hline 17 & Ribosomal protein Po & RPLPO & 12654583 & (K)TSFFQALGITTK(I) & $5.42 / 34,274$ \\
\hline 18 & Heat-shock $27-k D a$ protein 1 & HSPB1 & 4504517 & (R)LFDQAFGLPR(L) & $5.98 / 22,782.6$ \\
\hline 19 & Phosphoglycarate mutase 1 & PGAM1 & 38566176 & (R)VLIAAHGNSLR(G) & $6.68 / 28,520.1$ \\
\hline 20 & $\begin{array}{l}\text { Platelet-activating factor } \\
\text { acetylhydrolase }\end{array}$ & PAFAH1B3 & 4505587 & (R)VVLGGLPR(G) & $6.33 / 25,734.4$ \\
\hline
\end{tabular}

Table 1. List of proteins identified by LC-MS/MS analysis 

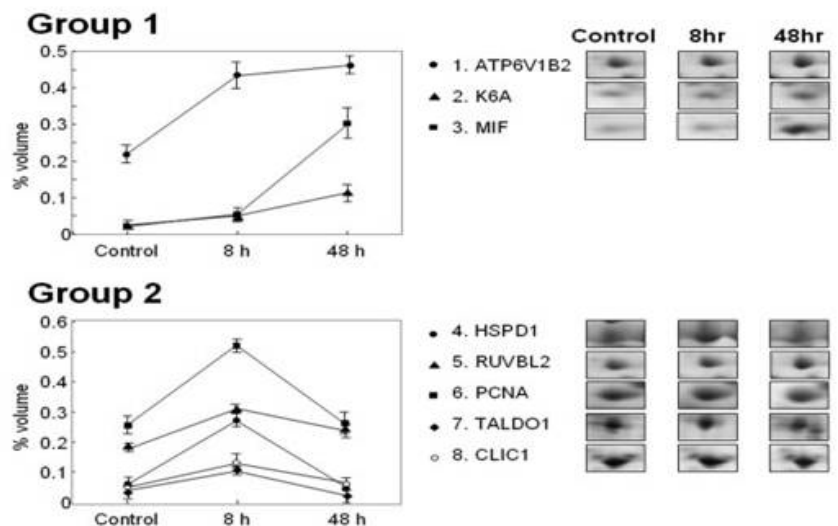

\section{Group 3}
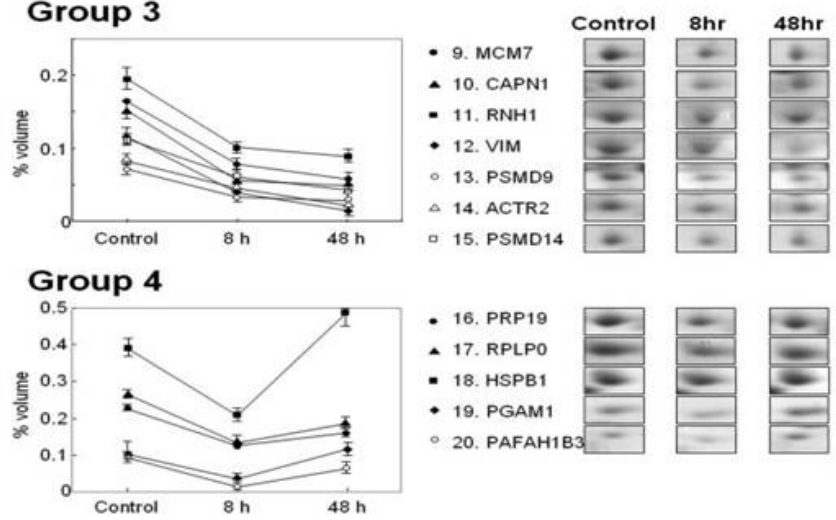

Figure 4. Cluster analysis of 20 proteins with significant differential expression ( $>2$-fold change) at 8 or $48 \mathrm{~h}$ caused by $\mathrm{TiO} 2$ treatment of BEAS-2B epithelial cells. The expression profiles of the individual proteins were classified by cluster analysis. Protein names (National Center for Biotechnology Information (NCBI)) are displayed for each cluster.

However, there is a lack of evidence showing a direct relationship between particulates and the induction of Th2-like cytokines, including IL-4 and IL-13. TiO2 particles are a component of PM 10 found in dusty workplaces in industries involved in the crushing and grinding of the mineral ore rutile (Templeton, 1994). Garabrant et al. (1987) reported that $50 \%$ of $\mathrm{TiO} 2$-exposed workers have respiratory symptoms accompanied by reduced pulmonary function. Because acute and chronic exposures to $\mathrm{TiO} 2$ particles also induce inflammatory responses in the airways and alveolar spaces of rats (Ahn et al., 2005, Kang et al., 2005, Schapira et al., 1995, Waheit et al., 1997), TiO2-treated rats are good models for studying epithelial responses to PM10 particles. Proteomics has been successfully used to examine oxidative stress at the cellular level (Xiao et al., 2003). PM10 or DEP increase lung inflammation by inhalant allergens or respiratory viral infection by acting as adjuvants. The response may enhance already existing allergies or IgE responses to neo-allergens and susceptibility to respiratory infection. This adjuvant effect is exerted by the enhanced 
production of inflammatory Th2 and/or Th1 cytokines (Diaz-Sanchez et al., 1997). In animal experiments and human studies, several cytokines and CC chemokines including IL-4, IL-5, IL-13, GM-CSF, RANTES, MCP-3, MIP-1 were increased when lymphocytes and macrophages/monocytes were co-stimulated with particulates in the presence of specific allergens (Hamilton et al., 2004). The immune system responds in different ways depending on the type of particulate. DEP favors a Th2 response, while asbestos fiber and carbon particles upregulate both Th1 and Th2 cytokines produced by autologous lymphocyte stimulated by antigen (Hamilton et al., 2004). In addition to the adjuvant effects, inhaled inert particles cause a spectrum of pulmonary responses, ranging from minimal changes to marked acute and chronic inflammation.

\section{Oxidative stress}

ROS production and the generation of oxidative stress are relevant to lung diseases. Oxygen is readily reduced with an electron to form oxygen free radicals, such as superoxide (Bast, et al., 2010, Finkel, 2011, Comhair \& Erzyrum, 2010). Superoxide takes up a second electron, leading to hydrogen peroxide, which will generate the extremely reactive hydroxyl radical in the presence of iron ions. Hydroxyl radicals react very quickly with biomolecules, such as proteins, fatty acids, and DNA (Bast, et al., 2010, Finkel, 2011, Comhair \& Erzyrum, 2010). All molecules in the direct vicinity of the hydroxyl radical will react with this reactive form of oxygen (Bast, et al., 2010, Finkel, 2011, Comhair \& Erzyrum, 2010). The various forms of oxygen are called ROS (Bast, et al., 2010). Formation of ROS takes place constantly in every cell during normal metabolic processes (Bast, et al., 2010, Finkel, 2011, Ballaban, et al., 2005, Comhair \& Erzyrum, 2010). Cellular sites for production of ROS include mitochondria,

microsomes, and enzymes (e.g., xanthine oxidase, P450 monooxygenase, cyclooxygenase, lipoxygenase, indole amine dioxygenase, monoamine oxidase) (Nadeem, et al., 2008). One of the most dangerous forms of PM pollution is diesel exhaust particles. Diesel exhaust particles consist of polyaromatic hydrocarbons, hydrophobic molecules that can diffuse easily through cell membranes. As free radicals cause oxidative damage to biological macromolecules, such as DNA, lipids, and protein, they are believed to be involved in the pathogenesis of many diseases (Tredaniel, et al., 1994). The particles are able to induce the generation of free radicals, which may lead to an increase in oxidative stress, exacerbating some respiratory symptoms. Metals present on the particle surface, including $\mathrm{Fe}, \mathrm{Co}, \mathrm{Cr}$, and $\mathrm{V}$, undergo redox cycling, while $\mathrm{Cd}, \mathrm{Hg}$, and $\mathrm{Ni}$, as well as $\mathrm{Pb}$, deplete glutathione and protein-bound sulfhydryl groups resulting in ROS production (Stohs, et al., 2001, Valko, et al., 2005). Metal-induced oxidative stress has been shown to subsequently affect the immune system, by causing neutrophilic lung injury and release of inflammatory mediators by several lung cell types (Ghio \& Delvin, 2001), and to act as the cornerstone for subsequent particle-induced inflammation (Dye et al., 1999). Another mechanism involves phagocytosis, characterized by the removal of microorganisms and pollutant particles (Forman \& Toress, 2001), and an essential element of the immune defense system, which may mediate alveolar macrophage binding of certain inert and environmental particulate matter, such as $\mathrm{Fe}_{2} \mathrm{O}_{3}$, silicates, $\mathrm{TiO}_{2}$, quartz, and iron oxide (Cha et al., 2007). Redox reactions regulate signal transduction as important chemical processes. The response of a cell to a reactive oxygen- 
rich environment often involves the activation of numerous intracellular signaling pathways, which can cause transcriptional changes and allow the cells to respond appropriately to the perceived oxidative stress (Finkel, 2011, Comhair \& Erzyrum, 2010). Nuclear factor- $\kappa \mathrm{B}(\mathrm{NF}-\kappa \mathrm{B})$ and activation protein-1 (AP-1) are regulated and influenced by the redox status and have been implicated in the transcriptional regulation of a wide range of genes involved in oxidant stress and cellular response mechanisms (Beamer \& Holian, 2005). In the nucleus, redox affects histone acetylation and deacetylation status, which at least partly regulates inflammatory gene expression by activation of redox-sensitive transcription factors (Liu, et al., 2005). NF- $\kappa \mathrm{B}$ is activated in epithelial cells and inflammatory cells during oxidative stress, leading to the upregulation of a number of proinflammatory genes (Beamer \& Holian, 2005). NF- $\kappa B$ is a protein heterodimer made up of p65 and p50 subunits. There is evidence of activation of NF- $\kappa B$ in bronchial mucosa and sputum inflammatory cells in asthmatic patients (Rhaman, et al., 1996). Many of the inflammatory genes responsible for the pathogenesis of asthma are regulated by NF-kB. AP1 is a protein dimer composed of a heterodimer of Fos and Jun proteins. AP-1 regulates many of the inflammatory and immune genes in oxidant-mediated diseases. Gene expression of gamma-glutamylcysteine synthetase, the rate-limiting enzyme for GSH synthesis, is induced by the activation of AP-1. In addition, the family of mitogen-activated protein kinases (MAPKs) is directly or indirectly altered by redox changes (Ciencewicki, et al., 2008). Oxidative stress and other stimuli, such as cytokines, activate various signal transduction pathways leading to activation of transcription factors, such as NF-kB and AP1 (Rahman \& Adcock, 2006). Binding of transcription factors to DNA elements leads to recruitment of CREB-binding protein (CBP) and/or other co-activators to the transcriptional initiation complex on the promoter regions of various genes (Rahman \& Adcock, 2006). Activation of CBP leads to acetylation of specific core histone lysine residues by an intrinsic histone acetyltransferase activity (Rahman \& Adcock, 2006). Redox changes also can activate members of the MAPK, such as extracellular signal-regulated kinase, c-jun N-terminal kinase, p38 kinase, and phosphoinositol-3 kinase, all of which may ultimately promote inflammation (Carvalho, et al., 2004). Both STAT1 and STAT3 activation are regulated by redox (Carvalho, et al., 2004). NF-E2-related factor 2, a basic leucine zipper transcription factor, involved in induction of the antioxidant element (ARE)-mediated transcriptional response is known to play an important role and binds to the ARE and upregulates the expression of several antioxidant genes in response to a variety of stimuli (Nguyen, et al., 2003). ROS (Nadeem, et al., 2008) can influence airway cells and reproduce many of the pathophysiological features associated with asthma by initiating lipid peroxidation, altering protein structure, enhancing release of arachidonic acid from cell membranes, contracting airway smooth muscle, increasing airway reactivity and airway secretions, increasing vascular permeability, increasing the synthesis and release of chemoattractants, inducing the release of tachykinins and neurokinins, decreasing cholinesterase and neutral endopeptidase activities, and impairing the responsiveness of $B$-adrenergic receptors (Barnes, et al., 1998). Asthma attacks and experimental allergen challenge are associated with immediate formation of superoxide that persists throughout the late asthmatic response (Calhoun, et al., 1992). Allergen challenge in the airways of atopic individuals 
caused a twofold increase in superoxide generation (Calhoun, et al., 1992). Spontaneous and experimental allergen-induced asthma attacks lead to eosinophil and neutrophil activation, during which NADPH oxidase is activated and ROS such as superoxide and its dismutation product $\mathrm{H}_{2} \mathrm{O}_{2}$ are rapidly formed (Klebanoff, 1980). ROS production by asthmatics correlates with the severity of airway reactivity (Calhoun, et al., 1992). Asthma is characterized by oxidative modifications (Sansers, et al., 1995). Increased levels of EPO and MPO parallel the numbers of eosinophils and neutrophils, respectively, and are found at higher than normal levels in asthmatic peripheral blood, induced sputum, and BAL fluid (Sansers, et al., 1995). Malondialdehyde and thiobarbituric acid-reactive substances have also been detected in urine, plasma, sputum, and BAL fluid in relation to the severity of asthma (Mondino, et al., 2004, Wood, et al., 2005) In addition, 8-isoprostane, a biomarker of lipid peroxidation, is also elevated in exhaled breath condensate from adults and children with asthma (Mondino, et al., 2004, Wood et al, 2005). Generation of reactive oxygen and nitrogen species is markedly increased during acute asthma attacks (MacPherson, et al., 2001, Wu, et al., 2000). The loss of SOD contributes to oxidative stress during acute episodes of asthma exacerbation (MacPherson et al, 2001, Wu et al, 2000). Oxidative modification of MnSOD is present in asthmatic airway epithelial cells (Malik \& Storey, 2011).The loss of SOD activity reflects the increased oxidative and nitrative stress in asthmatic patients, suggesting that SOD may serve as a surrogate marker of oxidant stress and asthma severity (Takaku, et al., 2011). ROS, such as superoxide and hydrogen peroxide, enhance vascular endothelial growth factor (VEGF) expression (Kuroki, et al., 1996), while exogenous SOD prevents VEGF expression (Kuroki, et al., 1996), suggesting that the increased vascularization found in asthma may be due to the involvement of oxidative stress via effects on hypoxia-inducible factors (Ghosh, et al., 2003). The catalase activity was found to be $50 \%$ lower in BAL fluid of asthmatic lungs than that in healthy controls (Ghosh, et al., 2003). Tyrosine oxidant modifications of catalase occur in asthma, such as chlorination of tyrosine by peroxidase-catalyzed halogenation, and oxidative cross-linking of tyrosine as monitored by dityrosine, a product of tyrosyl radicals (Ghosh, et al., 2003). The most extensive modification found in asthmatic lungs is tyrosine chlorination, which is 20-fold more extensive than tyrosine nitration (Ghosh, et al., 2003). In contrast to SODs and catalase, extracellular GPx is present at higher than normal levels in the lungs of individuals with asthma (Comhair, et al., 2002). This increase is due to induction of GPx mRNA and protein expression by bronchial epithelial cells in response to increased intracellular or extracellular ROS [94]. During asthma exacerbation in humans, the levels of serum TRX1 increase and are inversely correlated with airflow (Yamada, et al., 2003). Cigarette smoke can induce increased oxidant burden and cause irreversible changes to the antioxidant protective effects in the airways (van Der Troorn, et al., 2007). The smokederived oxidants damage airway epithelial cells inducing direct injury to membrane lipids, proteins, carbohydrates, and DNA, leading to chronic inflammation (Foronjy, et al., 2008). Cigarette smoking delivers and generates oxidative stress within the lungs (Lin \& Thoma, 2010) These imbalances of oxidant burden and antioxidant capacity have been implicated as important contributing factors in the pathogenesis of COPD (Lin \& Thoma, 2010) However, smoking also causes the depletion of antioxidants, which further contributes to oxidative tissue damage (Lin \& Thoma, 2010) The downregulation of antioxidant pathways has also 
been associated with acute exacerbations of COPD (Lin \& Thoma, 2010). Disruption of the oxidant/antioxidant balance is important in the pathogenesis of acute lung injury and acute respiratory distress syndrome. Different cytokines and growth factors play a role in the pathogenesis of lung fibrosis (Hecker, et al., 2009). ROS mediate the formation of TGF- $\beta$ in lung epithelial cells (Hecker, et al., 2009). Fibroblasts of patients with idiopathic pulmonary fibrosis produce $\mathrm{H}_{2} \mathrm{O}_{2}$ upon stimulation with TGF- $\beta$. This interplay between $\mathrm{H}_{2} \mathrm{O}_{2}$ and TGF$\beta$ leads to deterioration of re-epithelialization and fibrosis (Hecker, et al., 2009).

\section{Conclusions}

Epidemiological surveys and animal studies together suggest that air pollutants are involved in the pathogenesis of airway inflammation and aggravate respiratory symptoms. Avoidance of harmful exposures is a key component of national and international guideline recommendations for the management of respiratory diseases. Controlling air pollution is important for the prevention of airway diseases. Finally, in vitro and in vivo studies are needed to further delineate the role of particulate air pollutants in airway diseases and the molecular mechanisms involved.

\section{Author details}

An-Soo Jang

Division of Allergy and Respiratory Medicine, Department of Internal Medicine, Soonchunhayg University Hospital, Bucheon, Korea

\section{Acknowledgement}

This subject is supported by Korea Ministry of Environment (2012001360001) as "The Environmental Health Action Program".

\section{References}

Ahn M.H., Kang C.M., Park C.S., Park S.J., Rhim T., Yoon P.O., Chang H.S., Kim S.H., Kyono H., Kim K.C. (2005). Titanium dioxide particle-induced goblet cell hyperplasia: association with mast cells and IL-13. Respir Res, 6, 34.

Ayres, J.G., Borm, P., Cassee, F.R., Castranova, V., Donaldson, K., Ghio, A., Harrison, R.M., Hider, R., Kelly, F., Kooter, I.M., Marano, F., Maynard, R.L., Mudway, I., Nel, A., Sioutas, C., Smith, S., Baeza-Squiban, A., Cho, A., Duggan, S., Froines, J. (2008). Evaluating the toxicity of airborne particulate matter and nanoparticles by measuring oxidative stress potential - a workshop report and consensus statement. Inhal. Toxicol ,20, 75-99.

Baldi, I., Tessier, J.F., Kauffmann, F., Jacqmin-Gadda, H., Nejjari, C., Salamon, R. (1999). Prevalence of asthma and mean levels of air pollution: results from the French PAARC 
survey. Pollution Atomosphérique et Affections Respiratoires Chroniques. Eur Respir J, 14,132-138.

Barnes, P.J., Chung, K.F., Page, C.P. (1998). nflammatory mediators of asthma: an update. Pharmacol Rev, 50, 515-596.

Bast, A., Weseler, A. R., Haenen, G. R., den Hartog, G.J. (2010) Oxidative stress and antioxidants in interstitial lung disease. Curr Opin Pulm Med, 16, 516-520.

Beamer, C.A., Holian, A. (2005). Scavenger receptor class A type I/II (CD204) null mice fail to develop fibrosis following silica exposure. Am J Physiol Lung Cell Mol Physiol, 289, 186-195.

Beelen, R., Hoek, G., van den Brandt, P.A., Goldbohm, R.A., Fischer, P., Schouten, L.J., Jerrett, M., Hughes, E., Armstrong, B., Brunekreef, B. (2008). Long-term effects of trafficrelated air pollution on mortality in a Dutch cohort (NLCS-AIR study). Environ Health Perspect, 116, 196-202.

Bierbaum S., Nickel R., Koch A., Lau S., Deichmann K.A., Wahn U., et al.(2005). Polymorphisms and haplotypes of acid mammalian chitinase are associated with bronchial asthma. Am J Respir Crit Care Med, 172, 1505-1509.

Blackford, J.A., Jr, Jones, W., Dey, R.D., Castranova, V. (1997). Comparison of inducible nitric oxide synthase gene expression and lung inflammation following intratracheal instillation of silica, coal, carbonyl iron, or titanium dioxide in rats. J Toxicol Environ Health, 51, 203-218.

Breysse, P.N., Diette, G.B., Matsui, E.C., Butz, A.M., Hansel, N.N., McCormack, M.C. (2010). Indoor air pollution and asthma in children. Proc Am Thorac Soc, 7, 102-106.

Brunekreef, B., Janssen, A.H., de Hartog, J., Harssema, H., Knape, M., van Vliet, P. (1997). Air pollution from truck traffic and lung function in children living near motoways. Epidemiology , 8, 298-303.

Carvalho, H., Evelson, P., Sigaud, S., González-Flecha, B. (2004). Mitogen-activated protein kinases modulate $\mathrm{H}(2) \mathrm{O}(2)$-induced apoptosis in primary rat alveolar epithelial cells. $J$ Cell Biochem, 92, 502-513.

Cha, M.H., Rhim, T., Kim, K.H., Jang, A.S., Paik, Y.K., Park, C.S. (2007). Proteomic identification of macrophage migration-inhibitory factor upon exposure to $\mathrm{TiO} 2$ particles. Mol Cell Proteomics, 6, 56-63.

Ciencewicki, J., Trivedi, S., Kleeberger, S.R. (2008). Oxidants and the pathogenesis of lung diseases. J Allergy Clin Immunol, 122, 456-468.

Comhair, S.A., Erzurum, S.C. (2010). Redox control of asthma: molecular mechanisms and therapeutic opportunities. Antioxid Redox Signal, 12, 93-124.

Comhair, S.A., Erzurum, S.C. (2002). Antioxidant responses to oxidant-mediated lung diseases. Am J Physiol Lung Cell Mol Physiol, 283, 246-255.

D'Amato, G., Cecchi, L., D'Amato, M., Liccardi, G. (2010). Urban air pollution and climate change as environmental risk factors of respiratory allergy: an update. J Investig Allergol Clin Immunol, 20, 95-102.

Diaz-Sanchez, D., Tsien, A., Fleming, J., Saxon, A. (1997). Combined diesel exhaust particulate and ragweed allergen challenge markedly enhances human in vivo nasal 
ragweed-specific IgE and skews cytokine production to a T helper cell 2-type pattern. $J$ Immunol, 158, 2406-2413.

Donaldson, K., Tran, C.L. (2002). Inflammation caused by particles and fibers. Inhal. Toxicol, $14,5-27$.

Dye, J.A., Adler, K.B., Richards, J.H., Dreher, K.L. (1999). Role of soluble metals in oil fly ash-induced airway epithelial injury and cytokine gene expression. Am J Physiol, 277, L498-510.

Finkel, T. (2011). Signal transduction by reactive oxygen species. J Cell Biol, 194, 7-15.

Garabrant, D.H., Fine, L.J., Oliver, C., Bernstein, L., Peters, J.M. (1987). Abnormalities of pulmonary function and pleural disease among titanium metal production workers. Scand J Work Environ Health, 13, 47-51.

Folinsbee, L.J. (1992). Does nitrogen dioxide exposure increase airways responsiveness? Toxicol Indust Health, 8, 273-283.

Forman, H.J., Torres, M. (2001). Redox signaling in macrophages. Mol Aspects Med, 22, 189216.

Foronjy, R., Alison, W., D'Aarmiento, J. (2008). The pharmokinetic limitations of antioxidant treatment for COPD. Pulm Pharmacol Ther, 21, 370-379.

Fujii, T., Hayashi, S., Hogg, J.C., Vincent, R., Van Eeden, S.F. (2001). Particulate matter induces cytokine expression in human bronchial epithelial cells. Am J Respir Cell Mol Biol, 25, 265-271.

Gergen, P.J., Fowler, J.A., Maurer, K.R., Davis, W.W., Overpeck, M.D. (1998). The burden of environmental tobacco smoke exposure on the respiratory health of children 2 months through 5 years of age in the United States: Third National Health and Nutrition Examination Survey, 1988 to 1994. Pediatrics, 101, E8.

Ghio, A.J., Devlin, R.B. (2001). Inflammatory lung injury after bronchial instillation of air pollution particles. Am J Respir Crit Care Med, 164, 704-708.

Ghosh, S., Masri, F., Comhair, S. et al.(2003). Nitration of proteins in murine model of asthma. Am J Respir Crit Care Med, 167, 889.

Gielen, M.H., van der Zee, S.C., van Wijnen, J.H., van Steen, C.J., Brunekreef, B. (1997). Acute effects of summer air pollution on respiratory health of asthmatic children. Am J Respir Crit Care Med, 155, 2105-2108.

Grigg, J. (2009). Particulate matter exposure in children: relevance to chronic obstructive pulmonary disease. Proc Am Thorac Soc, 6, 564-569.

Guo, L., Johnson, R.S., Schuh, J.C. (2000). Biochemical characterization of endogenously formed eosinophilic crystals in the lungs of mice. J Biol Chem, 275, 8032-8037.

Hamelmann, E., Schwarze, J., Takeda, K., Oshiba, A., Larsen, G.L., Irvin, C.G., Gelfand, E.W. (1997). Noninvasive measurement of airway responsiveness in allergic mice using barometric plethysmography. Am J Respir Crit Care Med, 156, 766-775.

Hamilton, R.F. Jr, Holian, A., Morandi, M.T. (2004). A comparison of asbestos and urban particulate matter in the in vitro modification of human alveolar macrophage antigenpresenting cell function. Exp Lung Res, 30, 147-162. 
Hecker, L., Vittal, R., Jones, T., Jagirdar, R., Luckhardt, T.R., Horowitz, J.C., Pennathur, S., Martinez, F.J., Thannickal, V.J. (2009). NADPH oxidase- 4 mediates myofibroblasts activation and fibrogenic responses to lung injury. Nat Med, 15, 1077-1081.

Hirsch, T., Weiland, S.K., von Mutius, E., Safeca, A.F., Gräfe, H., Csaplovics, E., Duhme, H., Keil, U., Leupold, W. (1999). Inner city air pollution and respiratory health and atopy in children. Eur Respir J, 14, 669-677.

Holgate, S.T. (1999). The epidemic of allergy and asthma. Nature, 402, B2-B4.

Diette, G.B., McCormack, M.C., Hansel, N.N., Breysse, P.N., Matsui, E.C.(2008). Environmental issues in managing asthma. Respir Care, 53,602-615, discussion 616-617.

Jang, A.S., Choi, I.S., Lee, J.U., Park, S.W., Lee, J.H., Park, C.S. (2004). Changes in the expression of NO synthase isoforms after ozone: the effects of allergen exposure. Respir Res, $5,5$.

Jang, A.S., Yeum, C.H., Son, M.H. (2003). Epidemiologic evidence of a relationship between airway hyperresponsiveness and exposure to polluted air. Allergy, 58, 585-588.

Jiang, R., Bell, M.L. (2008). A comparison of particulate matter from biomassburning rural and non-biomass-burning urban households in northeastern China. Environ Health Perspect, 116, 907-914.

Jin, H.M., Copeland, N.G., Gilbert, D.J., Jenkins, N.A., Kirkpatrick, R.B., Rosenberg, M. (1998). Genetic characterization of the murine $\mathrm{Ym} 1$ gene and identification of a cluster of highly homologous genes. Genomics, 54, 316-322.

Kang, C.M., Jang, A.S., Ahn, M.H., Shin, J.A., Kim, J.H., Choi, Y.S., Rhim, T.Y., Park, C.S. (2005). Interleukin-25 and interleukin-13 production by alveolar macrophages in response to particles. Am J Respir Cell Mol Biol, 33, 290-296.

Koenig, J.Q., Mar, T.F., Allen, R.W., Jansen, K., Lumley, T., Sullivan, J.H., Trenga, C.A., Larson, T., Liu, L.J. (2005). Pulmonary effects of indoor- and outdoor-generated particles in children with asthma. Environ Health Perspect, 113, 499-503.

Koenig, J.Q. (1999). Air pollution and asthma. J Allergy Clin Immunol, 104, 717-722.

Klebanoff, S.J. (1980). Oxygen metabolism and the toxic properties of phagocytes. Ann Intern Med, 93, 480-489.

Kreit, J.W., Gross, K.B., Moore, T.B., Lorenzen, T.J., D'Arcy, J., Eschenbacher, W.L. (1989). Ozone-induced changes in pulmonary function and bronchial responsiveness in asthmatics. J Appl Physiol, 66, 217-222.

Kuipers, I., Guala, A.S., Aesif, S.W., Konings, G., Bouwman, F.G., Mariman, E.C., Wouters, E.F., Janssen-Heininger, Y.M., Reynaert, N.L. (2011). Cigarette smoke targets glutaredoxin 1, increasing s-glutathionylation and epithelial cell death. Am J Respir Cell Mol Biol, 45, 931-937.

Kuroki, M., Voest, E.E., Amano, S., Beerepoot, L.V., Takashima, S., Tolentino, M., Kim, R.Y., Rohan, R.M., Colby, K.A., Yeo, K.T., Adamis, A.P. (1996). Reactive oxygen intermediates increase vascular endothelial growth factor expression in vitro and in vivo. J Clin Invest, 98, 1667-1675.

Laden, F., Schwartz, J., Speizer, F.E., Dockery, D.W. (2006). Reduction in fine particulate air pollution and mortality: Extended follow-up of the Harvard Six Cities study. Am J Respir Crit Care Med, 173, 667-672. 
Laumbach, R.J. (2010). Outdoor air pollutants and patient health. Am Fam Physician, 81, 175180.

Li, J.J., Muralikrishnan, S., Ng, C.T., Yung, L.Y., Bay, B.H. (2010). Nanoparticle-induced pulmonary toxicity. Exp Biol Med, 235, 1025-1033

Li, N., Sioutas, C., Cho, A., Schmitz, D., Misra, C., Sempf, J., Wang, M., Oberley, T., Froines, J., Nel, A. (2003). Ultrafine particulate pollutants induce oxidative stress and mitochondrial damage. Environ Health Perspect, 111, 455-460.

Liu, H., Colavitti, R., Rovira, I.I., Finkel, T. (2005). Redox-dependent transcriptional regulation. Circ Res, 97, 967-974.

MacPherson, J.C., Comhair, S.A., Erzurum, S.C., Klein, D.F., Lipscomb, M.F., Kavuru, M.S., Samoszuk, M.K., Hazen, S.L. (2001). Eosinophils are a major source of nitric oxidederived oxidants in severe asthma: Characterization of pathways available to eosinophils for generating reactive nitrogen species. J Immunol, 166, 5763-5772.

Malik, A. I., Storey, K. B. (2011). Transcriptional regulation of antioxidant enzymes by FoxO1 under dehydration stress, Gene, 485, 114-119.

Matthay, R.A. (1992). Chronic airway diseases, in: J.B. Wyngaarden (Ed.), Cecil Textbook of Medicine, 19th ed.,W.B. Saunders, Philadelphia, 386-394.

McConnell, R., Berhane, K., Gilliland, F., Molitor, J., Thomas, D., Lurmann, F., Avol, E., Gauderman, W.J., Peters, J.M. (2003). Prospective study of air pollution and bronchitic symptoms in children with asthma. Am J Respir Crit Care Med, 168, 790-797.

McCormack, M.C., Breysse, P.N., Hansel, N.N., Matsui, E.C., Tonorezos, E.S., CurtinBrosnan, J., Williams, D.L., Buckley, T.J., Eggleston, P.A., Diette, G.B. (2008). Common household activities are associated with elevated particulate matter concentrations in bedrooms of inner-city Baltimore pre-school children. Environ Res, 106, 148-155.

McCreanor, J., Cullinan, P., Nieuwenhuijsen, M.J., Stewart-Evans, J., Malliarou, E., Jarup L., Harrington, R., Svartengren, M., Han, I. K., Ohman-Strickland, P., Chung, K.F., Zhang, J. (2007), Respiratory effects of exposure to diesel traffi c in persons with asthma. $N$ Engl J Med, 357, 2348-2358.

Mortimer, K.M., Neas, L.M., Dockery, D.W., Redline, S., Tager, I.B. (2002). The effect of air pollution on inner-city children with asthma. Eur Respir J, 19, 699-705.

McDonnell, W.F., Abbey, D.E., Nishino, N., Lebowitz, M.D. (1999). Long-term ambient ozone concentration and the incidence of asthma in nonsmoking adults: the AHSMOG study. Environ Res, 80, 110-121.

Moncada, S., Palmer, R.M., Higgs, E.A. (1991). Nitric oxide: physiology, pathophysiology and pharmacology. Pharmacol Rev, 143, 109-142.

Moshammer, H., Hoek, G., Luttmann-Gibson, H., Neuberger, M.A., Antova, T., Gehring, U., Hruba, F., Pattenden, S., Rudnai, P., Slachtova, H., Zlotkowska, R., Fletcher, T. (2006). Parental smoking and lung function in children: an international study. Am J Respir Crit Care Med, 173, 1255-1263.

Mondino, C., Ciabattoni, G., Koch, P., Pistelli, R., Trové, A., Barnes, P.J., Montuschi, P. (2004). Effects of inhaled corticosteroids on exhaled leukotrienes and prostanoids in asthmatic children. J Allergy Clin Immunol, 114, 761-767. 
Nadeem, A., Masood, A., Siddiqui, N. (2008). Oxidant--antioxidant imbalance in asthma: scientific evidence, epidemiological data and possible therapeutic options. Ther Adv Respir Dis, 2, 215-235.

Nel, A., Xia, T., Madler, L., Li, N. (2006). Toxic potential of materials at the nanolevel. Science, 311, 622-627.

Nicolai, T. (1999). Air pollution and respiratory disease in children: what is the clinically relevant impact? Pediatr Pulmonol Suppl, 18, 9-13.

Nguyen, T., Sherratt, P.J., Pickett, C.B. (2003). Regulatory mechanisms controlling gene expression mediated by the antioxidant response element. Annu Rev Pharmacol Toxicol, 43, 233-260.

Pagan, I., Costa, D.L., McGee, J.K., Richards, J.H., Dye, J.A. (2003). Metal mimic airway epithelial injury induced by in vitro exposure to Utah Valley ambient particulate matter extracts. J Toxicol Environ Health A, 66, 1087-1112.

Peters, J.M., Avol, E., Gauderman, W.J., Linn, W.S., Navidi, W., London, S.J., Margolis, H., Rappaport, E., Vora, H., Gong, H. Jr, Thomas, D.C. (1999). A study of twelve Southern California communities with differing levels and types of air pollution. II. Effects on pulmonary function. Am J Respir Crit Care Med, 159, 768-775.

Pierse, N., Rushton, L., Harris, R.S., Kuehni, C.E., Silverman, M., Grigg, J. (2006). Locally generated particulate pollution and respiratory symptoms in young children. Thorax, 61, 216-220.

Pope, C.A. 3rd, Kanner, R.E. (1993). Acute effects of PM10 pollution on pulmonary function of smokers with mild to moderate chronic obstructive pulmonary disease. Am Rev Respir Dis, 147, 1336-1340.

Pope, C.A. III, Ezzati, M., Dockery, D.W. (2009). Fine-particulate air pollution and life expectancy in the United States. N Engl J Med, 360, 376-386.

Pope III, C.A. (1991). Respiratory hospital admissions associated with PM10 pollution in Utah, Salt lake, and Cahe Valleys. Arch Environ Health, 46, 90-97

Pope, C.A., Dockery, D.W. (2006). Health effects of fine particulate air pollution: lines that connect. J. Air Waste Manage Assoc, 56, 709-742.

Pruss-Ustun, A., Corvalan, C. (2006). Preventing disease through healthy environments: towards an estimate of the environmental burden of disease. Geneva, Switzerland: World Health Organization.

Rahman, I., Adcock, I.M. (2006). Oxidative stress and redox regulation of lung inflammation in COPD. Eur Respir J, 28, 219-242.

Rahman, I., Smith, C.A., Lawson, M.F., Harrison, D.J., MacNee, W. (1996). Induction of gamma-glutamylcysteine synthetase by cigarette smoke is associated with AP-1 in human alveolar epithelial cells. FEBS Lett, 396, 21-25.

Ristovski, Z.D., Miljevic, B., Surawski, N.C., Morawska, L., Fong, K.M., Goh, F., Yang, I.A. (2011). Respiratory health effects of diesel particulate matter. Respirology, 29. doi: 10.1111/j.1440-1843.2011.02109.x. [Epub ahead of print]

Sacks, J.D., Stanek, L.W., Luben, T.J., Johns, D.O., Buckley, B.J., Brown, J.S., Ross, M. (2011). Particulate matter-induced health effects: who is susceptible? Environ Health Perspect, $119,446-454$. 
Sanders, S.P. Zweier, J.L. Harrison, S.J., Trush, M.A., Rembish, S.J., Liu, M.C. (1995). Spontaneous oxygen radical production at sites of antigen challenge in allergic subjects. Am J Respir Crit Care Med, 151, 1725-1733.

Schäfer, T., Ring, J. (1997). Epidemiology of allergic diseases. Allergy, 52(38 Suppl), S14-22.

Schapira, R.M., Ghio, A.J., Effros, R.M., Morrisey, J., Almagro, U.A., Dawson, C.A., Hacker, A.D. (1995). Hydroxyl radical production and lung injury in the rat following silica or titanium dioxide instillation in vivo. Am J Respir Cell Mol Biol, 12, 220-226.

Schwartz, J., Slater, D., Larson, T.V., Pierson, W.E., Koenig, J.Q. (1993). Particulate air pollution and hospital emergency room visits for asthma in Seattle. Am Rev Respir Dis, 147, 826-831.

Schindler, C., Keidel, D., Gerbase, M.W., Zemp, E., Bettschart, R., Brändli, O., Brutsche, M.H., Burdet, L., Karrer, W., Knöpfli, B., Pons, M., Rapp, R., Bayer-Oglesby, L., Künzli, N., Schwartz, J., Liu, L.J., Ackermann-Liebrich, U., Rochat, T.; SAPALDIA Team. (2009). Improvements in PM10 exposure and reduced rates of respiratory symptoms in a cohort of Swiss adults (SAPALDIA). Am J Respir Crit Care Med, 179, 579-587.

Seaton, A., MacNee, W., Donaldson, K., Godden, D. (1995). Particulate airpollution and acute health effects. Lancet, 345, 176-178.

Seagrave, J. (2008). Mechanisms and implications of air pollution particle associations with chemokines. Toxicol App. Pharmacol, 232, 469-477.

Song, H.M., Jang, A.S., Ahn, M.H., Takizawa, H., Lee, S.H., Kwon, J.H., Lee, Y.M., Rhim, T.Y., Park, C.S. (2008). Ym1 and Ym2 expression in a mouse model exposed to diesel exhaust particles. Environ Toxicol, 23, 110-116.

Sun, Y.J., Chang, N.C., Hung, S.I., Chang, A.C., Chou, C.C., Hsiao, C.D. (2001). The crystal structure of a novel mammalian lectin, Ym1, suggests a saccharide binding site. J Biol Chem, 276, 17507-17514.

Stohs, S.J., Bagci, D., Hassoun, E., Bagchi, M. (2001). Oxidative mechanisms in the toxicity of chromium and cadmium ions. J Environ Pathol Toxicol Oncol, 20, 77-88.

Stone, V., Johnston, H., Clift, M.J.D. (2007). Air pollution, ultrafine and nanoparticle toxicology: Cellular and molecular interactions. IEEE T Nanobiosci, 6, 331-340.

Takaku, Y., Nakagome, K., Kobayashi, T., Hagiwara, K., Kanazawa, M., Nagata, M. (2011). IFN- $\gamma$-inducible protein of $10 \mathrm{kDa}$ upregulates the effector functions of eosinophils through $\beta 2$ integrin and CXCR3. Respir Res, 17, 138.

Templeton, D.M. (1994). Titanium, in Handbook on metals in clinical and analytic chemistry. In: Seiler HG, Siegel A, Siegel H, eds. New York: Marcel Dekker, 627-630.

Totlandsdal, A.I., Cassee, F.R., Schwarze, P., Refsnes, M., Låg, M. (2010). Diesel exhaust particles induce CYP1A1 and pro-inflammatory responses via differential pathways in human bronchial epithelial cells. Part Fibre Toxicol , 7, 41.

Valko, M., Morris, H., Cronin, M.T. (2005). Metals, toxicity and oxidative stress. Curr Med Chem, 12, 1161-1208.

van Der Toorn, M., Smit-de Vries, M.P., Slebos, D.J., de Bruin, H.G., Abello, N., van Oosterhout, A.J., Bischoff, R., Kauffman, H.F. (2007). Cigarette smoke irreversibly modifies glutathione in airway epithelial cells. Am J Physiol Lung Cell Mol Physiol, 293, 1156-1162. 
Winickoff, J.P., Berkowitz, A.B., Brooks, K., Tanski, S.E., Geller, A., Thomson, C., Lando, H.A., Curry, S., Muramoto, M., Prokhorov, A.V., Best, D., Weitzman, M., Pbert, L.; Tobacco Consortium, Center for Child Health Research of the American Academy of Pediatrics. et al. (2005). State-of-the-art interventions for office-based parental tobacco control. Pediatrics, 115, 750-760.

Ward, J.M., Yoon, M., Anver, M.R., Haines, D.C., Kudo, G., Gonzalez, F.J., Kimura, S. (2001). Hyalinosis and $\mathrm{Ym} 1 / \mathrm{Ym} 2$ gene expression in the stomach and respiratory tract of 129S4/SvJae and wild-type and CYP1A2-null B6, 129 mice. Am J Pathol, 158, 323-332.

Warheit, D.B., Hansen, J.F., Yuen, I.S., Kelly, D.P., Snajdr, S.I., Hartsky, M.A. (1997). Inhalation of high concentrations of low toxicity dusts in rats results in impaired pulmonary clearance mechanisms and persistent inflammation. Toxicol Appl Pharmacol, $145,10-22$.

Welch, J.S., Escoubet-Lozach, L., Sykes, D.B., Liddiard, K., Greaves, D.R., Glass, C.K. (2002). TH2 cytokines and allergic challenge induce $\mathrm{Ym} 1$ expression in macrophages by a STAT6-dependent mechanism. J Biol Chem, 277, 42821-42829.

Wood, L.G., Garg, M.L., Simpson, J.L., Mori, T.A., Croft, K.D., Wark, P.A., Gibson, P.G. (2005). Induced sputum 8-isoprostane concentrations in inflammatory airway diseases. Am J Respir Crit Care Med, 171, 426-430.

Wu, W., Samoszuk, M.K., Comhair, S.A., Thomassen, M.J., Farver, C.F., Dweik, R.A., Kavuru, M.S., Erzurum, S.C., Hazen, S.L. (2000). Eosinophils generate brominating oxidants in allergen-induced asthma. J Clin Invest, 105, 1455-1463.

Xiao, G.G., Wang, M., Li, N., Loo, J.A., Nel, A.E. (2003). Use of proteomics to demonstrate a hierarchical oxidative stress response to diesel exhaust particle chemicals in a macrophage cell line. J Biol Chem, 278, 50781-50790.

Yamada, Y., Nakamura, H., Adachi, T., Sannohe, S., Oyamada, H., Kayaba, H., Yodoi, J., Chihara, J. (2003). Elevated serum levels of thioredoxin in patients with acute exacerbation of asthma. Immunol Lett, 86, 199-205.

Yang, W., Omaye, S.T. (2009). Air pollutants, oxidative stress and human health. Mutat Res, 674, 45-54.

Yang, Q., Chen, Y., Krewski, D., Burnett, R.T., Shi, Y., McGrail, K.M. (2005). Effect of shortterm exposure to low levels of gaseous pollutants on chronic obstructive pulmonary disease hospitalizations. Environ Res, 99, 99-105.

Zelikoff, J.T., Chen, L.C., Cohen, M.D., Fang, K., Gordon, T., Li Y., Nadziejko, C., Schlesinger, R.B. (2003). Effects of inhaled ambient particulate matter on pulmonary antimicrobial immune defense. Inhal Toxicol, 15, 131-150.

Zhu, Z., Zheng, T., Homer, R.J., Kim, Y.K., Chen, N.Y., Cohn, L., Hamid, Q., Elias, J.A. (2004). Acidic mammalian chitinase in asthmatic Th2 inflammation and IL-13 pathway activation. Science, 304, 1678-1682. 